\title{
Present status of small-scale exploitation of mangroves in Rekawa Lagoon, Sri Lanka
}

\author{
V.T.K. Dayarathne* and M.P. Kumara \\ Faculty of Fisheries and Marine Science, Ocean University of Sri Lanka, \\ Mahawela Road, Tangalle, Sri Lanka \\ *Corresponding author (sciencekelum@yahoo.com)
}

\begin{abstract}
Small-scale forest exploitation is reported to have significant impacts on the composition, structure, and regeneration of terrestrial forest types nevertheless, only a few studies have examined mangroves in this respect. Although information related to small-scale harvesting activities in mangroves helps management and conservation initiatives, such information is scanty for Sri Lanka. In order to address this knowledge gap, mangrove cutting/removal data were collected from Boraluwa mangrove community of Rekawa Lagoon $\left(6^{\circ} 03^{\prime} \mathrm{N} 80^{\circ} 50^{\prime} \mathrm{E}\right)$, Sri Lanka from 4 transects (30m long, $10 \mathrm{~m}$ wide; divided into $10 \mathrm{~m} \mathrm{x} 10 \mathrm{~m}$ sub-plots) laid perpendicular to the shoreline, in July -December, 2012. The percentage cutting observed during the time ranged from $0 \%$ to $17 \%$ between the sub-plots while Aegiceras corniculatum and Lumnitzera racemosa were found to be cut at a higher intensity (10\% and $21 \%$ respectively). Other mangrove species: Rhizophora mucronata, Excoecaria agallocha and Bruguiera gymnorrhiza reported only $1.0 \%$, $1.3 \%$ and $4.2 \%$ cutting intensities respectively. Thus the highly vulnerable species for cuttings were A .corniculatum and L. Racemosa. However, Kruskal-Wallis test did not show a significant difference of cutting intensities between the sub-plots ( $\mathrm{S}$ $=2.20, \mathrm{p}>0.05)$. The mean height of stems removed by cutting was $48.5 \mathrm{~cm}$ $( \pm 34.8)$ and $62.9 \mathrm{~cm}( \pm 44.7)$ for A. corniculatum and L. Racemosa respectively while $5.7 \mathrm{~cm}( \pm 3.35)$ and $5.2 \mathrm{~cm}( \pm 2.5)$ were their mean diameters respectively. The mean $\%$ sprouting of the cut stumps in the transects were $42 \%$, for A. corniculatum and it was $68 \%$ for L. racemosa. The mean number of sprouts $( \pm \mathrm{SD})$ per stump were $5.9( \pm 4.5)$ and $4.3( \pm 3.2)$ for A. corniculatum and L. racemosa respectively. Only $8 \%$ of intact trees of both $A$. corniculatum and $L$. racemosa were with diameters larger than $8 \mathrm{~cm}$ indicating that larger stems of these two species have been selectively cut in the recent past. As the tree diameter is proportional to the age of the trees, even small scale cutting could affect the age composition and reproductive capacity of the mangrove forests in Rekawa lagoon.
\end{abstract}

Keywords: Mangrove cutting, Sprouting, Rekawa lagoon, Sri Lanka 


\section{Introduction}

Mangroves form ecosystems characteristic to inter-tidal areas of tropical and subtropical coasts, and they are composed of variety of exclusive and associated species of plants as well as aquatic, semi-aquatic, terrestrial and aerial fauna. (Hogarth 1999; Kathiresan and Bingham 2001). Coastal inhabitants are variously benefited with ecological services generated by functions of mangrove ecosystems, such as production function in relation to provisioning food, medicine and timber, and regulatory function in erosion control, protection from extreme climatic events and habitat function that provides feeding, breeding, resting and protection services for various fauna (Hamilton and Snedaker 1984; Leh and Sasekumar 1984; Robertson and Blaber 1992; Sasekumar et al. 1992; Bennett and Reynolds 1993; Ruitenbeek 1994; Costanza et al. 1997; Bandaranayake 1998; Ronnback 1999). Small-scale mangrove exploitations cause significant impacts on forest structure but only a few studies (Eusebio et al. 1986; Smith and Berkes 1993; Walters 2005a, 2005b; Longonje and Dave 2012) have examined the effects of small scale cutting of mangroves on ecosystem structure and functioning. In the Philippines the size selective cutting has been responsible for almost $90 \%$ of stem mortality (Walters 2005a, 2005b). In Mida Creek, Kenya, selective removal of small sized poles by the users has stimulated forest regeneration (Kario et al. 2002). Thus, studies on mangrove harvesting can provide valuable information for forestry management and conservation initiatives.

Mangrove distribution in Sri Lanka is patchy and confined to narrow stands along estuaries and lagoons (CCD 1986; Karunathilake 2003). Although small scale cutting of mangroves is practiced in various Sri Lankan mangrove areas (DahdouhGuebas et al. 2000; Dayananda 2004; Atapattu and Nissanka 2005; Satyanarayana et al. 2013) its ecological impacts have poorly been studied.

The objectives of the present study therefore were to determine the intensity of mangrove removal and the potential effect of small scale mangrove cutting on vegetation structure of a selected mangrove stand in Rekawa lagoon.

\section{Materials and methods}

Four mangrove transects (30m long, $10 \mathrm{~m}$ wide) were selected from Boraluwa mangrove community of Rekawa Lagoon $\left(6^{\circ} 03^{\prime} \mathrm{N} ; 80^{\circ} 50^{\prime} \mathrm{E}\right)$, Sri Lanka and each transect was divided into three $10 \mathrm{~m} \times 10 \mathrm{~m}$ study blocks (Figure 1). Mangrove species present, diameter at breast height (dbh), species that have been cut and the condition of stumps (dead/alive/sprouting) were recorded at each block. The dbh was measured at the highest point possible in cases where stumps were cut below $1.3 \mathrm{~m}$ (Walters 2005a). The condition, height, dbh and the species of all the intact trees within the plots also were reported. All field data collections were completed between July and December, 2012.

Mean values were calculated for the stem densities (number ha ${ }^{-1}$ ), number of cut stumps, height and diameter of the stem at the point of cutting, the $\%$ 
sprouting of cut stems, \% cutting intensities (calculated summing all the species) along with standard deviations.
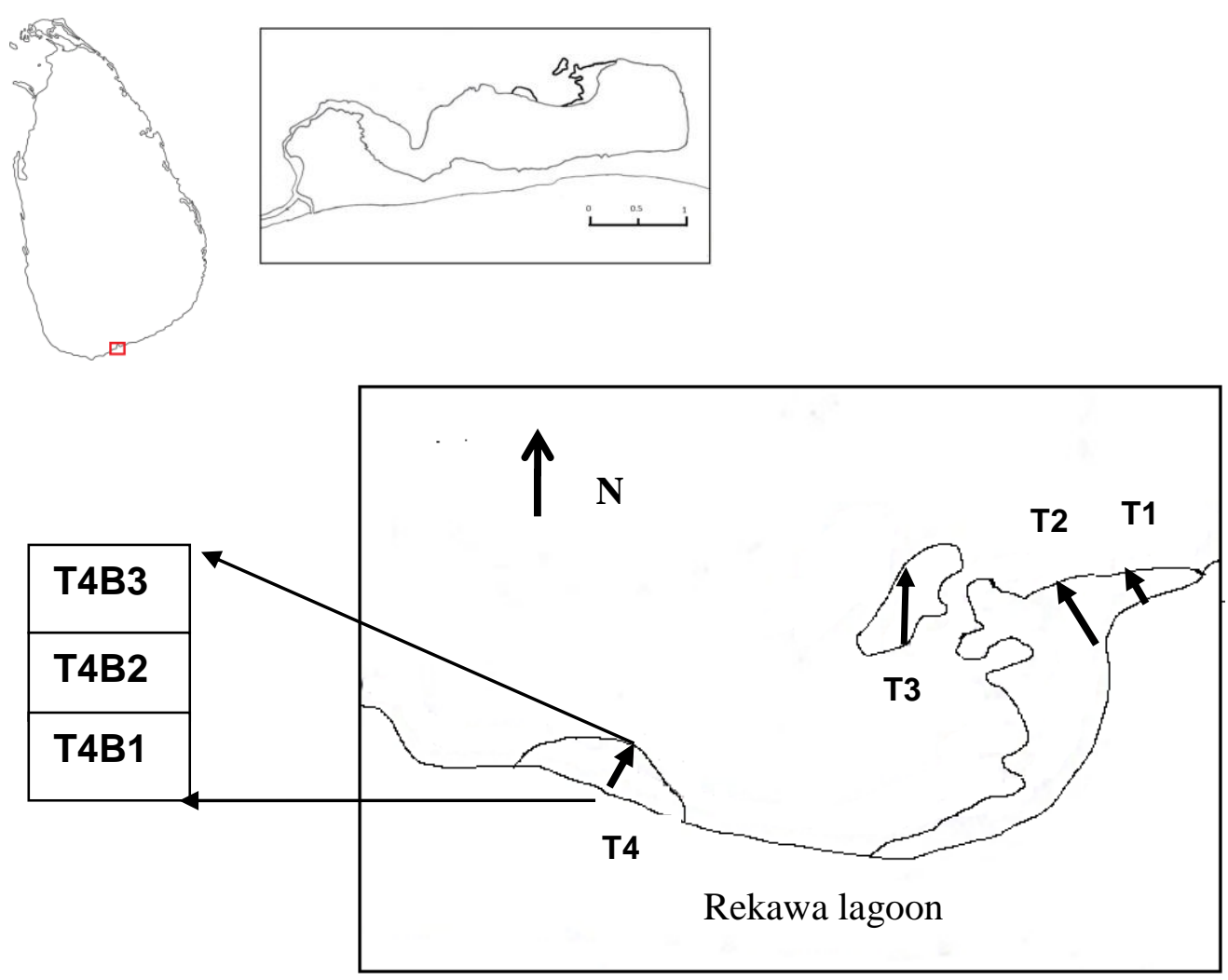

Figure 1. The study sites in Rekawa lagoon and location of the lagoon in Sri Lanka. T1-T4 are the locations of four transects. There are four blocks in each transect. The four blocks in the T4 transect are indicated as T4B1 - T4B3.

The relationship between the height at which the stems have been cut and the number of sprouts per stump were determined using regression analyses. Percentage cutting intensity and relative density (RD) were calculated as;

Percentage cutting intensity $=[$ number of cut trees/number of total (cut and intact) trees] $\times 100$

$\mathrm{RD}=[$ Density of the selected species/total density of all species $] \times 100$

As data were not normally distributed, the mean values were compared between the transects by Kruskal-Wallis tests for differences. 


\section{Results}

Mangrove species recorded from the studied transects were Lumnitzera racemosa, Aegiceras corniculatum, Bruguiera gymnorrhiza, Excoecaria agallocha, Rhizophora mcronata, Avicennia marina, Avicennia officinalis.

The values of $\%$ cutting intensities calculated summing all the species were not significantly different (Kruskal-Wallis tests: $\mathrm{S}=2.20, \mathrm{p}=0.532$ ) between the transects (Table 1). The values of $\%$ cutting intensities ranged from $0 \%$ to $17.1 \%$ between the blocks (Figure 2), while the maximum and minimum cutting intensities were recorded in T2B 2 and T2B1 blocks respectively. T2B1 was observed to have higher relative density (75.8\%) of $R$. mucronata that resulted $0 \%$ cutting intensity (Table 2).

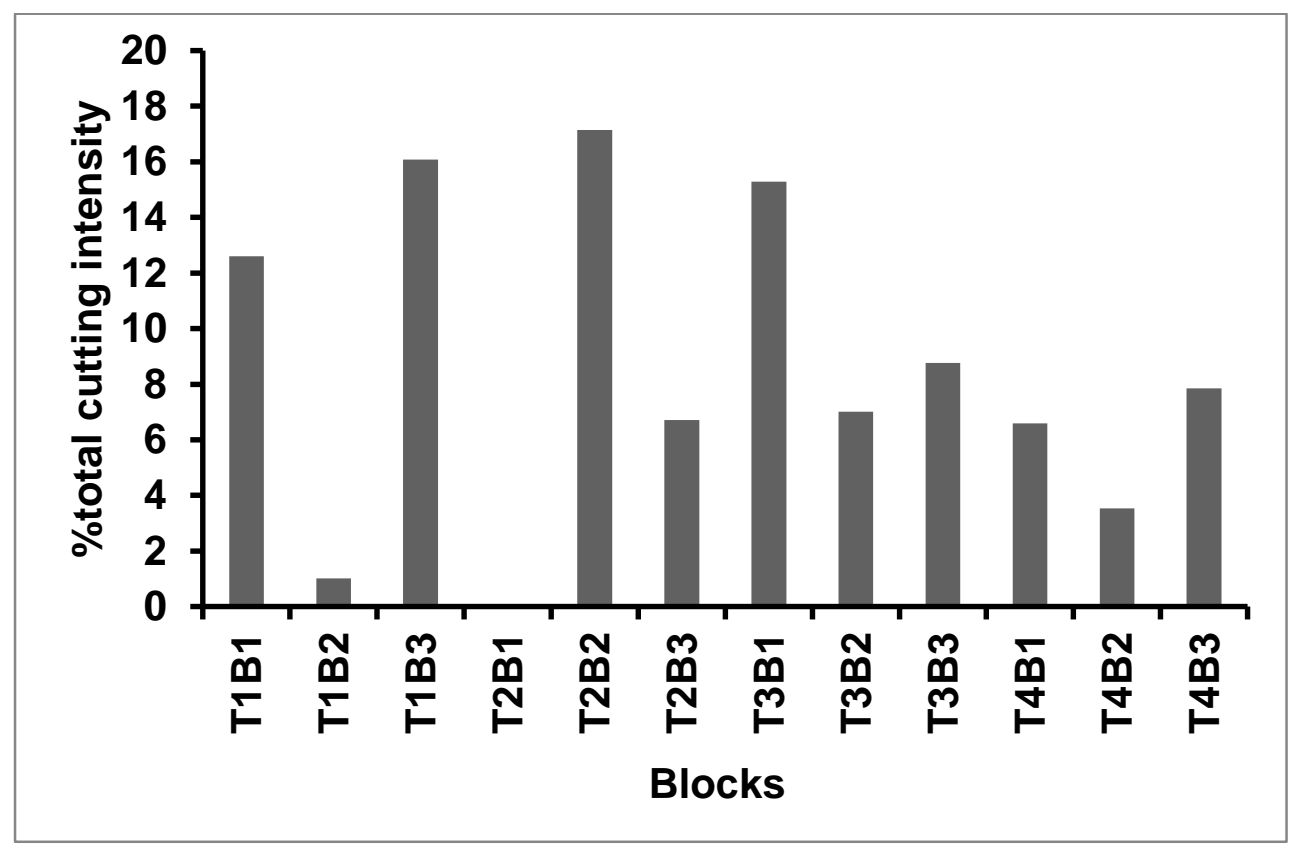

Figure 2. Percentage total cutting intensity between blocks

Table 1 . Total $\%$ cutting intensity and total stem density of non-cut trees.

\begin{tabular}{lcccc}
\hline & \multicolumn{4}{c}{ Transect Number } \\
\cline { 2 - 5 } & 1 & 2 & 3 & 4 \\
\hline $\begin{array}{l}\text { Cutting intensity \% } \\
\begin{array}{l}\text { Stem density of non- } \\
\text { cut trees }\end{array}\end{array}$ & $9.90 \pm 7.90$ & $7.93 \pm 8.62$ & $10.37 \pm 4.37$ & $5.97 \pm 2.22$ \\
\hline
\end{tabular}


Table 2. Relative density of species between blocks (cut+non-cut trees).

\begin{tabular}{lllllllll}
\hline Transect & Block & Rm & Lr & Ea & Ac & Am & Bg & Ao \\
\hline T 1 & B 1 & 9.1 & 57.9 & 26.4 & 6.7 & 0.0 & 0.0 & 0.0 \\
T 1 & B 2 & 1.0 & 15.3 & 61.2 & 16.3 & 6.1 & 0.0 & 0.0 \\
T 1 & B 3 & 0.0 & 53.3 & 0.0 & 46.7 & 0.0 & 0.0 & 0.0 \\
T 2 & B 1 & 75.8 & 12.1 & 10.6 & 0.0 & 0.0 & 1.5 & 0.0 \\
T 2 & B 2 & 3.8 & 36.2 & 50.5 & 1.9 & 0.0 & 7.6 & 0.0 \\
T 2 & B 3 & 2.2 & 20.1 & 50.7 & 17.2 & 0.0 & 9.7 & 0.0 \\
T 3 & B 1 & 0.0 & 0.9 & 26.4 & 70.4 & 0.0 & 0.0 & 2.3 \\
T 3 & B 2 & 0.0 & 12.5 & 22.6 & 65.0 & 0.0 & 0.0 & 0.0 \\
T 3 & B 3 & 0.0 & 7.0 & 12.3 & 78.9 & 0.0 & 1.8 & 0.0 \\
T 4 & B 1 & 17.6 & 25.3 & 30.8 & 24.2 & 1.1 & 1.1 & 0.0 \\
T 4 & B 2 & 0.0 & 3.5 & 44.2 & 50.4 & 1.8 & 0.0 & 0.0 \\
T 4 & B 3 & 2.0 & 21.6 & 41.2 & 27.5 & 7.8 & 0.0 & 0.0 \\
\hline
\end{tabular}

$\mathrm{Rm}=$ Rhizophora mcronata, Lr=Lumnitzera racemosa, , Ea=Excoecaria agallocha, $\mathrm{Ac}=$ Aegiceras corniculatum, $\mathrm{Am}=$ Avicennia marina, $\mathrm{Bg}=$ Bruguiera gymnorrhiza Ao=Avicennia officinalis

The species-wise \% cutting intensity averaged for all the transects ranged from 0 (A. marina and A. officinalis) to 21.3 (L. racemosa) (Table 3; Figure 3). The total intact stem densities (Kruskal-Wallis tests: $\mathrm{S}=3.40, \mathrm{p}=0.334$ ) were not significantly differed between the transects (Table 1).

Table 3. Species-wise \% cutting intensity and relative density.

\begin{tabular}{lcc}
\hline Species & \% Cutting intensity & $\begin{array}{c}\text { Relative Density } \\
\text { (cut+non-cut trees) }\end{array}$ \\
\hline L. racemosa & 21.3 & 25.4 \\
A.corniculatum & 10.4 & 37.1 \\
B. gymnorrhiza & 4.2 & 1.5 \\
E. agallocha & 1.3 & 29.0 \\
R. mucronata & 1.0 & 6.0 \\
A. marina, & 0.0 & 0.8 \\
A. officinalis & 0.0 & 0.3 \\
\hline
\end{tabular}


The mean height at which trees were cut ranged between $48.5 \mathrm{~cm}$ and 62.9 $\mathrm{cm}$ for the A. corniculatum and $L$. racemosa respectively while mean diameters $( \pm \mathrm{SD})$ were found to be $5.7 \mathrm{~cm}( \pm 3.35)$ and $5.2 \mathrm{~cm}( \pm 2.5)$ for the A. corniculatum and $L$. racemosa respectively. Ninety five percent of cut stumps in the transects were $L$. racemosa $(56 \%)$ and $A$. corniculatum (39\%). The sprouting percentages of the cut stumps within the blocks were $42.3 \%(n=59)$, and $68.1 \%(n=94)$ for $A$. corniculatum and $L$. racemosa respectively. The mean number of sprouts $( \pm \mathrm{SD})$ per stump was $5.9( \pm 4.5)$ and $4.3( \pm 3.2)$ for $A$. corniculatum and L. racemosa respectively. The mean $\%$ sprouting of the cut stumps within the transects was $42.3 \%$, and $68.1 \%$ for A. corniculatum and L. racemosa respectively. The number of sprouts per stump significantly increased with increasing cutting height for species.

Within the sub-plots, $91.9 \%$ of intact trees had diameter $<8 \mathrm{~cm}$ (Figure 4 ). Among the intact live trees in the sub-plots, $99.6 \%$ of A. corniculatum and $76.8 \%$ of $L$. racemosa trees had diameter $<8 \mathrm{~cm}$ (Figures 5 and 6 ).

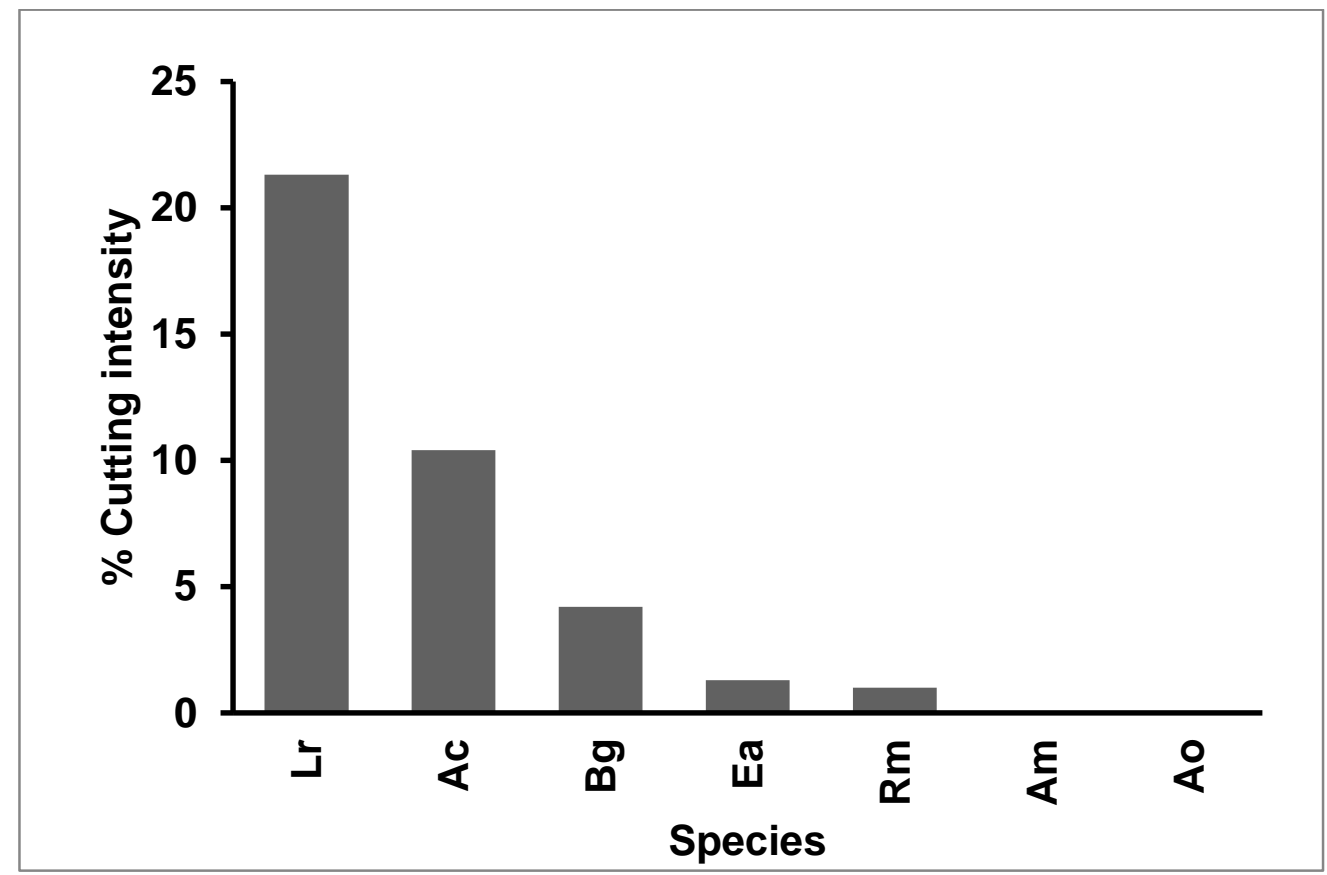

Figure 3. Species-wise cutting intensities averaged for the 4 transects. $\mathrm{Lr}=$ Lumnitzera racemosa, Ac=Aegiceras corniculatum, Bg=Bruguiera gymnorrhiza, Ea=Excoecaria agallocha, $\mathrm{Rm}=$ Rhizophora mcronata, Am=Avicennia marina, Ao=Avicennia officinalis . 
V.T.K Dayarathne \& M.P. Kumara /Sri Lanka J. Aquat. Sci. 20 (1) (2015): 11-22

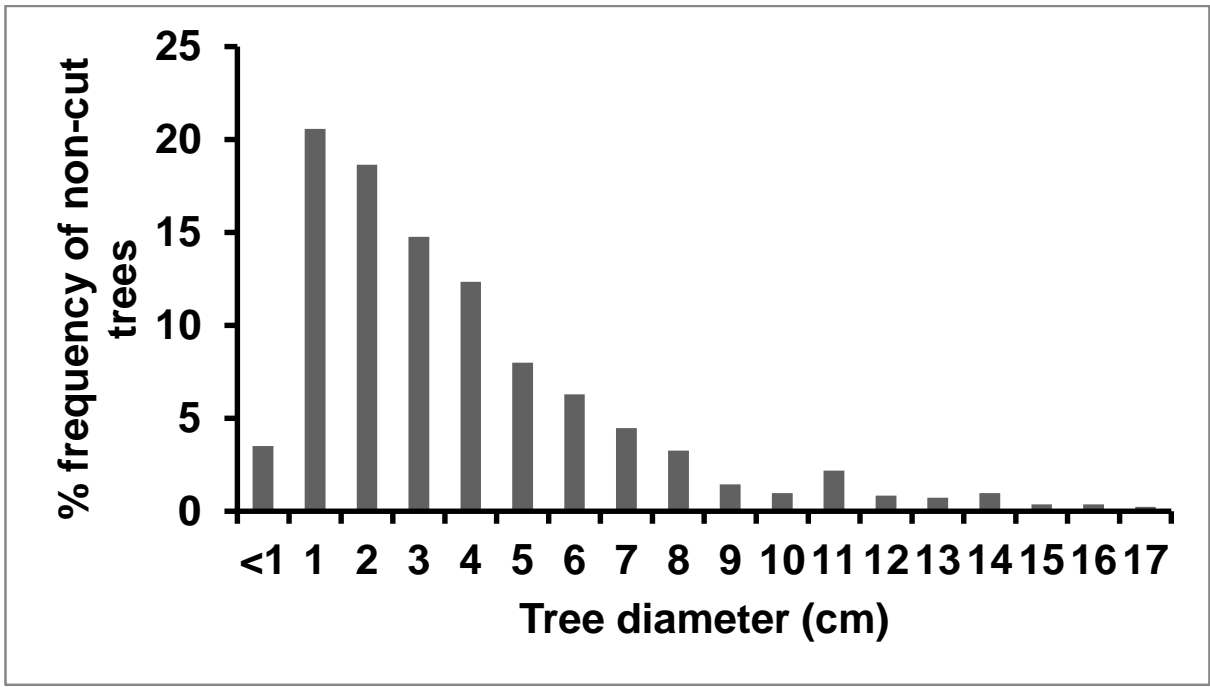

Figure 4. Diameter distribution of non-cut trees of A. corniculatum and $L$. tacemosa.

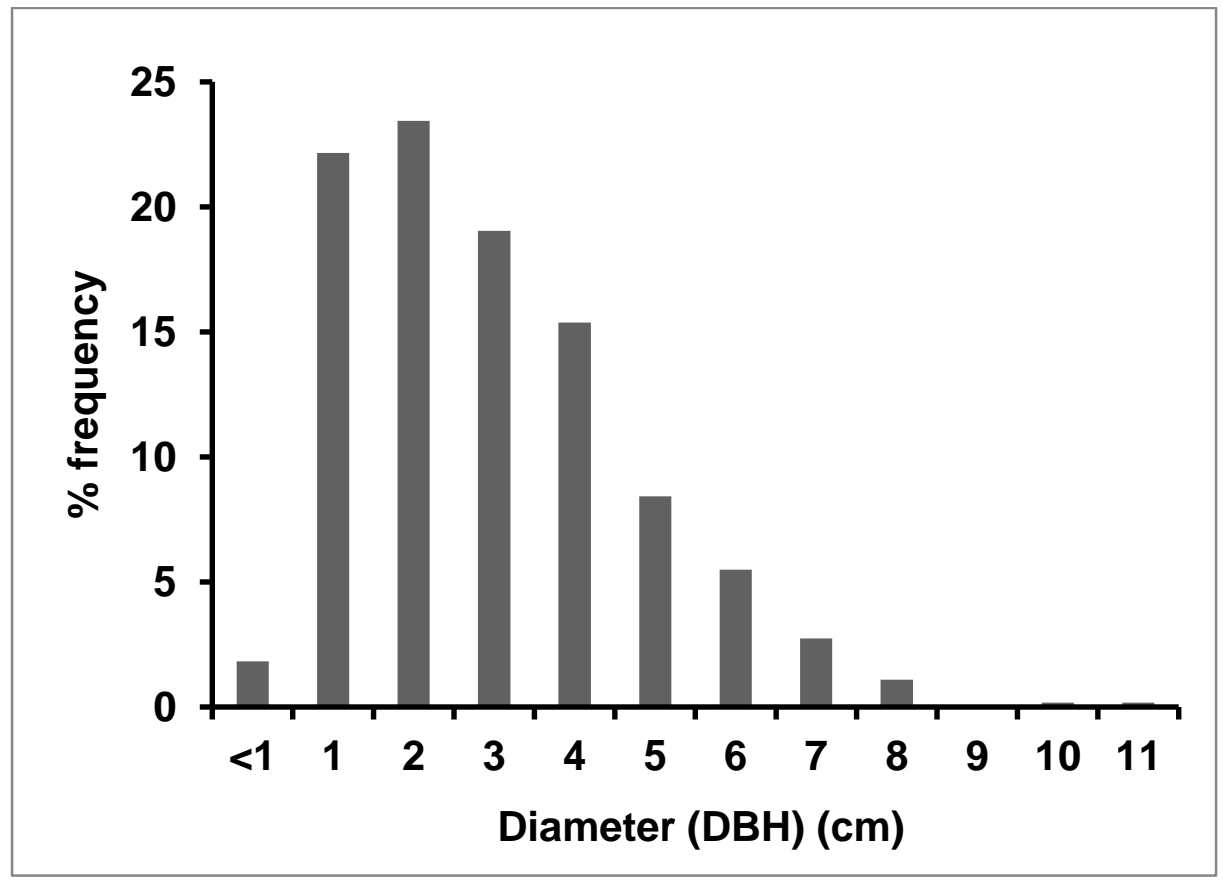

Figure 5. Diameter distribution of non-cut A. corniculatum trees. 


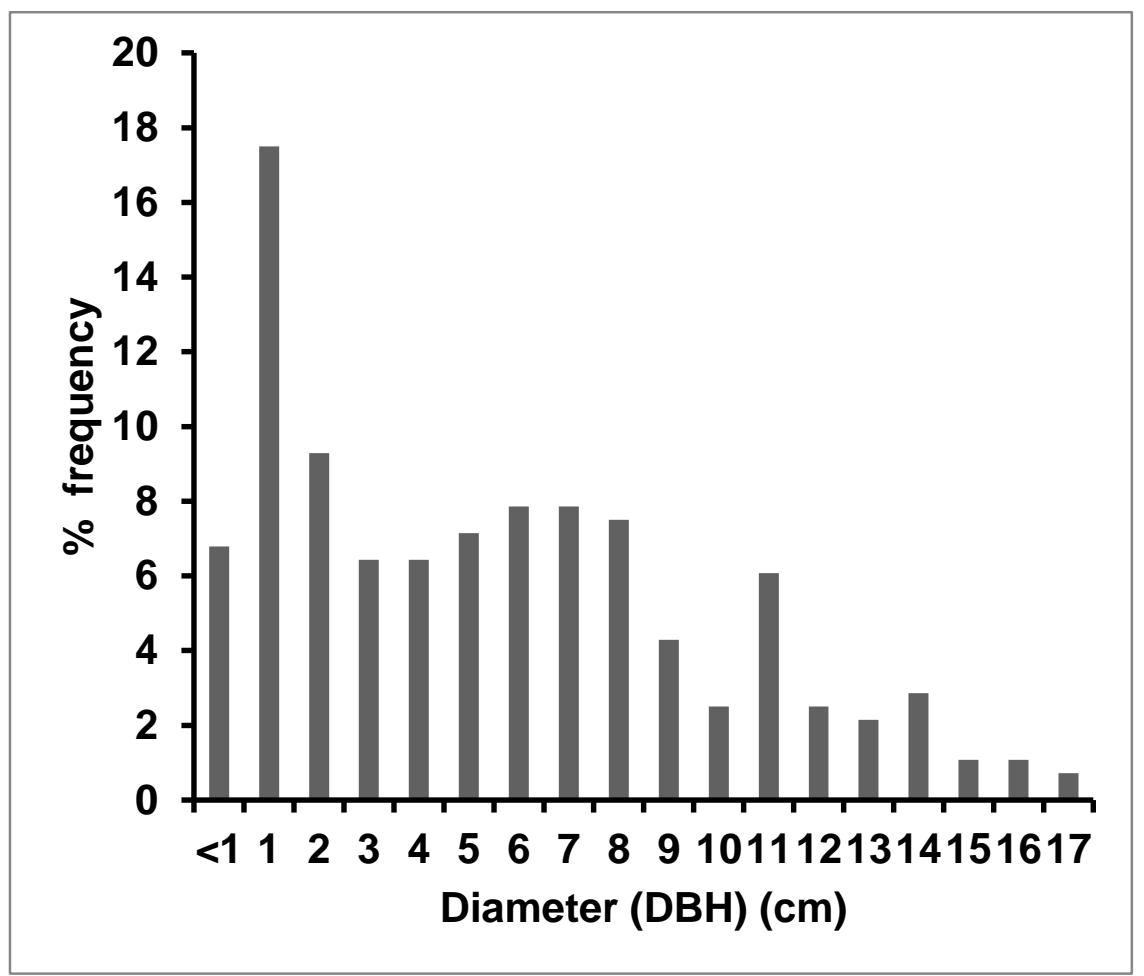

Figure 6. Diameter distribution of non-cut L. racemosa trees.

Among the trees that were cut, the highest percentage frequency was recorded at a diameter range of $4-5 \mathrm{~cm}$ for $L$. racemosa $(22.6 \%)$ and $A$. corniculatum (28.1\%) while $79.6 \%$ of $L$. racemosa and $91.2 \%$ of $A$. corniculatum trees that were cut (stumps) were within the diameter classes $3-8 \mathrm{~cm}$ (Figure 7). $L$. racemosa showed a significant relationship between total number of intact and cut trees (Figure 8). However, A. corniculatum did not show such a relationship. 
V.T.K Dayarathne \& M.P. Kumara /Sri Lanka J. Aquat. Sci. 20 (1) (2015): 11-22

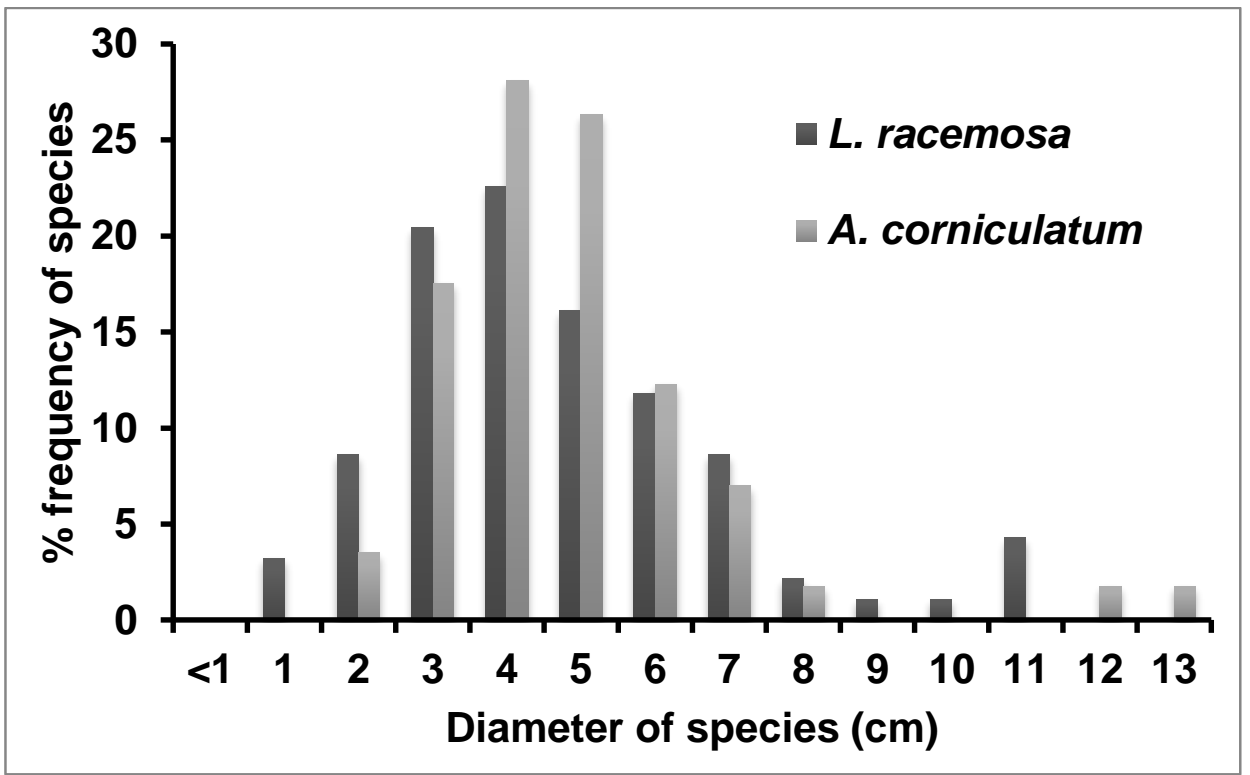

Figure 7. Diameter distribution of cut trees of L. racemosa and A. corniculatum.

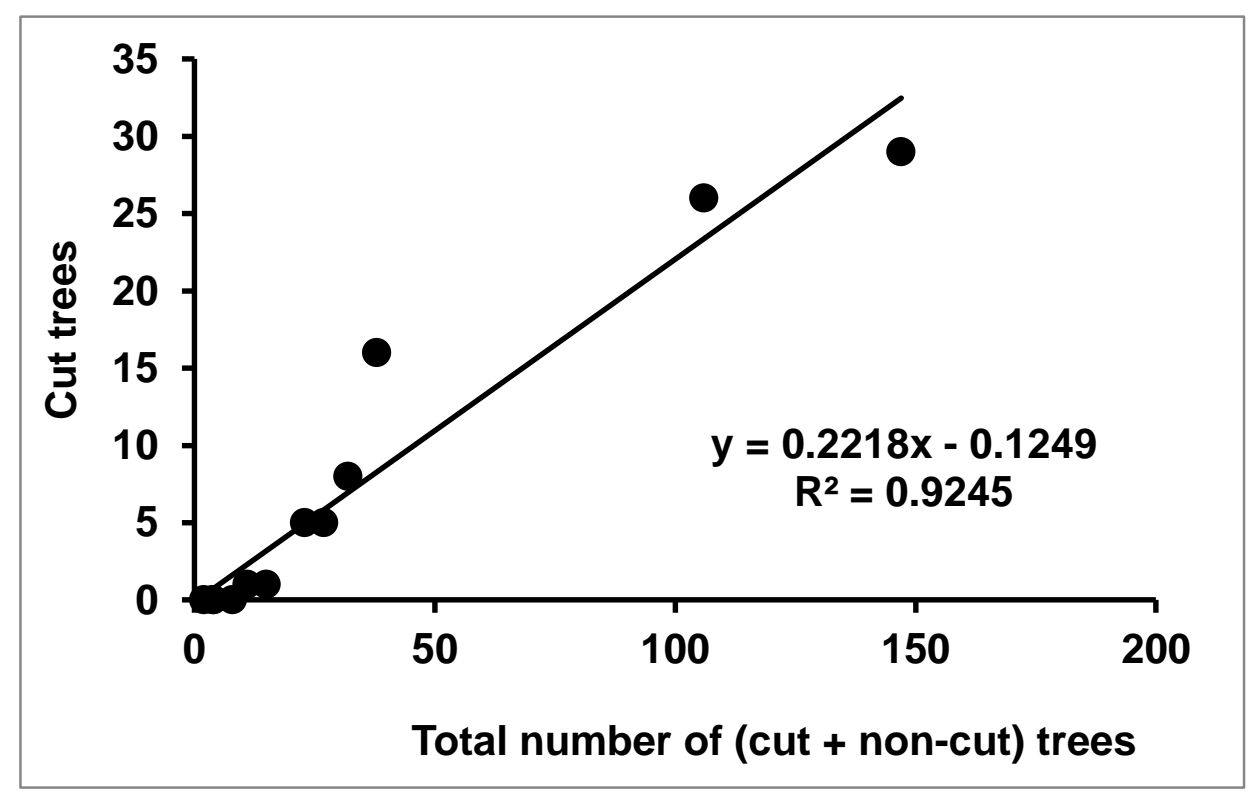

Figure 8. Relationship between the number of total (cut+non-cut) and cut $L$. racemosa in trees. 


\section{Discussion}

In terms of the \% cutting intensity, A .corniculatum and L. racemosa were highly vulnerable to small-scale harvesting among which the highest vulnerable species was $L$. racemosa. High wood density $\left(0.738 \mathrm{~g} \mathrm{~cm}^{-3}\right)$ and the slender-erect nature of the stems of $L$. racemosa is preferred for poles for fencing, handles of mamoties, rafts, and constructing frames for wattle and daub houses and to make wooden handles of utensils. Higher abundance of trees as indicated by higher relative densities (37.1 for A. corniculatum and 25.4 for L. racemosa) may also have attracted cutters towards the study area. A statistically significant relationship that was observed between the number of trees cut and the total (cut+intact) number of L. racemosa trees (Figure 8) indicates that people tend to cut mangroves from dense mangrove areas.

Although E. agallocha also had higher relative density (29.0), its low wood density $\left(0.390 \mathrm{~g} \mathrm{~cm}^{-3}\right)$, poor wood quality and the poisonous latex may have distracted people from cutting these trees. In general, higher relative densities of low vulnerable species reduce the total \% cutting intensity in some blocks while higher relative densities of high vulnerable species increase $\%$ cutting intensity in some other blocks. There are certain areas where there is mangrove cutting (e.g., $R$. mucronata in Plot T2B1; Table 2), but is not clear whether this is due to poor accessibility to the area or due to the reason that the people give relatively a higher value for $R$. mucronata as a mangrove species and hence refrain from cutting them or any other reason.

Dominance of low diameter $(<8 \mathrm{~cm})$ of $A$. corniculatum and L. racemosa tree stumps in the study area implies that the previous selective cutting operations have mainly focused on bigger trees. Since the tree diameter is proportionate to the age of the trees, small scale harvesting by the villagers appears to have removed mature trees that have higher reproductive capacity. Since the mature trees are the seed producers for natural regeneration process, removal of older trees would directly affect the regeneration potential of the forest. Species and size selective harvesting of mangroves also would affect the species composition of the forest affecting the structure and functioning of the forest.

Observation that $79.6 \%$ of $L$. racemosa and $91.2 \%$ of A. corniculatum trees that were cut had $3-8 \mathrm{~cm}$ diameter indicates that the villagers continue to harvest the younger trees of these species. Walters $(2005 \mathrm{a}, 2005 \mathrm{~b})$ found that the cutting can lead to $90 \%$ of tree mortality in mangroves. The tree mortality for the current study was $57.3 \%$ and $31.9 \%$ for L. racemosa and A. corniculatum respectively. This indicates that the coppicing rate (from the stumps) of these two species is high. The number of sprouts per stump appeared to increase in A. corniculatum and $L$. racemosa, when the stump length is high, i.e. when trees are cut at a greater height above ground, they are able to produce more new sprouts. However, this relationship was not statistically significant $(p>0.05)$. The tree bark plays an important role during sprouting of cut stumps and presence of greater extent of 
intact bark in stumps appears to result higher number of sprouts. However, more studies with a large sample sizes are needed to confirm this.

A. corniculatum and L. racemosa are the most exploited, especially as light timber, species in the mangrove vegetation at Boraluwa area of Rekawa lagoon. The level of exploitation of mangrove species appear to differ from one area to another, even in the same lagoon, depending on their habitat, utility value, abundance and growth characteristics.

\section{References}

Atapattu, U.G.A.M.K.S.S. \& C. Nissanka 2005. Present status of the fishery in Rekawa Lagoon, Sri Lanka. Proceedings of the Third Science Symposium, Faculty of Science, University of Ruhuna, Matara, Sri Lanka 3: 42-52.

Bandaranayake, W.M. 1998. Traditional and medicinal uses of mangroves. Mangroves and Salt Marshes 2: 133-148.

Bennett, E.L. \& C.J. Reynolds 1993. The value of a mangrove area in Sarawak. Biodiversity and Conservation 2: 359-375.

CCD, 1986. Master Plan on Coastal Erosion Management, Coast Conservation Department and Danish Hydraulic Institute, Colombo. 142 p.

Costanza, R., R. d'Arge, R. de Groot, S. Farber, M. Grasso, B. Hannon, K. Limburg, S. Naeem, R.V.J. Paruelo, R.G. Raskin, P. Sutton \& M. van den Belt 1997. The value of the world's ecosystem services and natural capital. Nature 387: 253-260.

Dahdouh-Guebas, F., A. Verheyden, W. De Genst, S. Hettiarachchi \& N. Koedam 2000. Four decade vegetation dynamics in Sri Lankan mangroves as detected from sequential aerial photography: a case study in Galle. Bulletin of Marine Science 67(2): 741-759.

Dayananda, L.P.D. 2004. Enhancing Sustainable Livelihoods. A Case Study from Wanathavilluwa, Sri Lanka Occasional Paper IUCN, Sri Lanka No. 6, iii + $36 \mathrm{p}$.

Eusebio, M.A., F.O. Tesoro \& D.M. Cabahug 1986. Environmental impact of timber harvesting on mangrove ecosystem in the Philippines. Mangroves of Asia and the Pacific: Status and Management. Natural Resource management Center, Ministry of Natural Resources, Quezon City, Philippines. pp 337-354.

Hamilton, L.S. \& S.C. Snedaker (eds) 1984. Handbook for Mangrove Area Management. UNEP and East West Center, Environment and Policy Institute, Honolulu. 126 p.

Hogarth, P.J. 1999. The Biology of Mangroves. Oxford University Press, Oxford. $228 \mathrm{p}$.

Kairo J.G., F. Dahdouh-Guebas, P.O. Gwada, C. Ochieng \& N. Koedam 2002. Regeneration status of mangrove forests in Mida Creek, Kenya: a compromised or secured future. Ambio 31: 562-568.

Karunathilake, K.M.B.C. 2003. Status of mangroves in Sri Lanka. Journal of Coastal Development 7(1): 5-9. 
Kathiresan, K. \& B.L. Bingham 2001. Biology of mangroves and mangrove ecosystems. Advances in Marine Biology 40: 82-93.

Leh, C.M.U. \& A. Sasekumar 1984. Feeding ecology of prawns in shallow water adjoining mangrove shores. pp. 331-353. In: Proceeding of Asian Symposium on Mangrove Environment: Research and Management. Ardyas, University of Malaya \& UNESCO.

Longonje, S.N. \& R. Dave 2012. Assessing ecosystem effects of small-scale cutting of Cameroon mangrove forests. Journal of Ecology and the Natural Environment 4(5): 126-134.

Robertson, A.I. \& S.J.M. Blaber 1992. Plankton, epibenthos and fish communities. pp. 173-224. In: A.I. Robertson \& D.M. Alongi (eds.) Tropical Mangrove Ecosystems. Coastal and Estuarine Studies No. 41. American Geophysical Union, Washington, DC.

Ronnback, P. 1999. The ecological basis for the economic value of mangrove forests in seafood production. Ecological Economics 29: 235-252.

Ruitenbeek, H.J. 1994. Modelling economy-ecology linkages in mangroves: economic evidence for promoting conservation in Bintuni Bay, Indonesia. Ecological Economics 10: 223-247.

Sasekumar, A., V.C. Chong, M.U. Leh \& R. D’cruz 1992. Mangrove as a habitat for fish and prawns. Hydrobiologia 247: 195-207.

Satyanarayana, B., S. Mulder, L.P. Jayatissa \& F. Dahdouh-Guebas 2013. Are the mangroves in the Galle-Unawatuna area (Sri Lanka) at risk? A socialecological approach involving local stakeholders for a better conservation policy. Ocean and Coastal Management 71: 225-237.

Smith, A.H. \& F. Berkes, 1993. Community-based use of mangrove resources in St. Lucia. International Journal of Environmental Studies 43:123-131.

Walters, B.B. 2005a. Ecological effects of small-scale cutting of Philippine mangrove forests. Forest Ecology and Management 206: 331-348.

Walters, B.B. 2005b. Patterns of local wood use and cutting of Philippine mangrove forests. Economic Botany 59: 66-76. 